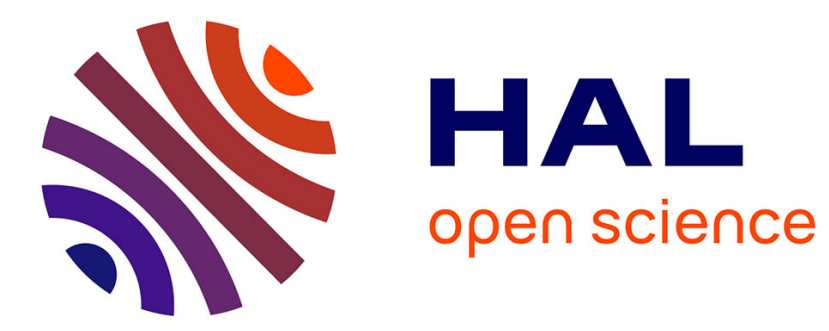

\title{
Multi-sensor imaging of plant stresses: Towards the development of a stress-catalogue
}

Laury Chaerle, Sándor Lenk, Ilkka Leinonen, Lyn Jones, Dominique van Der Straeten, Claus Buschmann

\section{- To cite this version:}

Laury Chaerle, Sándor Lenk, Ilkka Leinonen, Lyn Jones, Dominique van Der Straeten, et al.. Multisensor imaging of plant stresses: Towards the development of a stress-catalogue. Biotechnology Journal, 2009, 4 (8), pp.1152-n/a. 10.1002/biot.200800242 . hal-00495060

\section{HAL Id: hal-00495060 https://hal.science/hal-00495060}

Submitted on 25 Jun 2010

HAL is a multi-disciplinary open access archive for the deposit and dissemination of scientific research documents, whether they are published or not. The documents may come from teaching and research institutions in France or abroad, or from public or private research centers.
L'archive ouverte pluridisciplinaire HAL, est destinée au dépôt et à la diffusion de documents scientifiques de niveau recherche, publiés ou non, émanant des établissements d'enseignement et de recherche français ou étrangers, des laboratoires publics ou privés. 


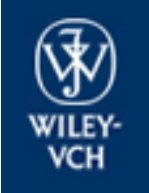

Biotechnology Journal

\section{Multi-sensor imaging of plant stresses: Towards the development of a stress-catalogue}

\begin{tabular}{|r|l|}
\hline Journal: & Biotechnology Journal \\
\hline Manuscript ID: & BIOT-2008-0242.R2 \\
\hline Wiley - Manuscript type: & Review \\
\hline Author: & $19-$ Mar-2009 \\
\hline Complete List of Authors: & $\begin{array}{l}\text { Chaerle, Laury; Ghent University } \\
\text { Lenk, Sándor; University of Karlsruhe } \\
\text { Leinonen, Ilkka; SCRI } \\
\text { Jones, Lyn; SCRI } \\
\text { Van Der Straeten, Dominique; University of Ghent } \\
\text { Buschmann, Claus; University of Karlsruhe }\end{array}$ \\
\hline Keywords: & $\begin{array}{l}\text { Fluorescence, Image processing , Re-absorption , Stress, } \\
\text { Thermography }\end{array}$ \\
\hline
\end{tabular}

\section{s) ScholaroNE" \\ Manuscript Central}




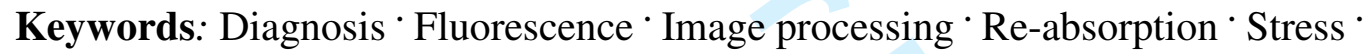
Thermography

Correspondence: Dr. Claus Buschmann, Botanical Institute II, University of Karlsruhe, D76128 Karlsruhe, Germany E-mail: claus.buschmann@botanik2.uni-karlsruhe.de Fax: +49-721-608-4874

Abbreviations: $C C D$, charged coupled device; Chl, chlorophyll; Chl-F, chlorophyll fluorescence; LED, light emitting diode; PS II, photosystem II; SA, salicylic acid; SWIR, short wavelength infra red; TMV, tobacco mosaic virus; UV, ultraviolet; VIS, visible 


\begin{abstract}
Agricultural production is limited by a wide range of abiotic (e.g. drought, waterlogging) and biotic (pests, diseases and weeds) stresses. The impact of these stresses can be minimized by appropriate management actions such as irrigation or chemical pesticide application. However further optimization requires the ability to diagnose and quantify the different stresses at an early stage. Particularly valuable information of plant stress responses is provided by (a) thermal imaging which primarily detects changes in transpiration rate and (b) fluorescence sensing which may indicate functioning of photosynthesis and other physiological processes. These can be supplemented by conventional video imagery for study of growth. An efficient early warning system would need to discriminate between different stressors. Given the wide range of sensors, and the association of specific plant physiological responses with changes at particular wavelengths, this goal seems within reach. This is based on the organization of the individual sensor results in a matrix that identifies specific signatures for multiple types of biotic and abiotic stress. In this paper we first review the diagnostic effectiveness of different individual imaging techniques, and then extend this to the multi-sensor stress-identification approach.

\&block;abstract shortened to 190 words, please check\&block;
\end{abstract}


In the 1930s, the term 'stress' was introduced as a human health syndrome by the Canadian medical researcher and endocrinologist of Hungarian origin Hans (János) Selye (1907-1982) [1]. Plant stress is defined as "a significant deviation from the conditions optimal for life" [2]. This definition implies that the occurrence of stress depends on the conditions to which a plant has acclimated. One can distinguish between abiotic (radiation, temperature, water, gases, minerals, mechanical effects) and biotic (induced by micro-organisms, animals, plants, anthropogenic factors) stresses.

In order to properly interpret the causes and effects of the different types of stress, it is usual to study single stresses under controlled conditions. Nevertheless such studies are of only partial relevance to natural conditions because plants are normally exposed to a multitude of interacting concurrent influences. Primary stress responses may be modified both by the acclimation and adaptation of the plants to the previous environmental factors, and by interactions with other organisms. As a further complicating factor the effect or impact of these stresses can vary with the developmental stage of the plant.

Stress does not necessarily need to be lethal. Mild stress conditions can lead to an increased resistance, which will help the plant to react to and overcome a subsequent stress (acquired stress resistance). This positive stress has also been termed 'eustress'. A strong stress may immediately lead to acute damage or later on - when there is not enough resistance - to chronic damage. A damaging stress is also called -'disstress' [3].

The importance of biotic and abiotic stresses on plant yield and their impact on agricultural production has been widely recognized. Therefore this subject has received ample attention in the last 20 years, as evidenced by multiple reviews and books with a wide range 
of ecophysiological topics [2-13] and others with focus on photosynthesis [14, 15], phytochemistry [16, 17] and air pollution [18].

This fact, together with the increasing awareness that stresses associated with global anthropogenic factors ('greenhouse effect', 'ozone hole') caused by industrialization may have substantial ecological and economic impacts, has led to the emergence of a large body of literature on detection of plant stresses and plant responses.

With the increasing pressure on available arable land and water resources, plant stress alleviation and avoidance will increase in importance in the near future. There is therefore an urgent need to improve techniques for the sensitive early detection, monitoring and diagnosis of stress to allow effective management responses. It is essential that the detection methods are rapid, non-destructive and low cost. The detection of stress-induced changes of physiological parameters is a focus of much recent and current basic and applied plant physiological research and a range of instruments have been developed in the past 20 years that aim to detect stress effects on plants in a non-contact way. The search for optimal imaging-derived stress detection parameters is still ongoing, while the advent of multi-sensor detection of a combination of parameters could effectively lead to the identification and subsequent remediation of emerging stresses. These aims are an integral part of precision agriculture, which strives to limit the inputs of nutrients, pesticides and herbicides by matching them to the actual crop needs, which would avoid unnecessary expenditures and detrimental impact on the environment and ultimately human health.

This review is based on an evaluation of stress detection by a range of imaging techniques including thermography and different types of fluorescence imaging that was undertaken in the frame of the EU-Research Training Network "STRESSIMAGING" but is extended to include a wide range of available information on stress-imaging at the leaf and plant level. Although we concentrate here on measurements applicable at the leaf- or plant-level the 
results here should provide a sound basis for interpretation of measurements at the canopy or field scale and for application at larger scales and in precision agriculture approaches. It is worth noting, however, that extension to the canopy or remote-sensing scales may provide yet further opportunities for incorporation of additional information useful for stress diagnosis.

The non-contact detection of stress is largely based on optical measurements of plant temperature (by thermal imaging) and fluorescence emission (for recent reviews: $[19,20]$ ). The latter two signals can be subdivided in spectral ranges by applying multi- or hyperspectral imaging. Thermography and chlorophyll fluorescence imaging are central in this review since they provide information on two key physiological parameters: transpiration and photosynthesis. In certain circumstances these may be supplemented by conventional digital imagery that allows, for example, measurement of growth. The most useful diagnostic information is obtained when several measured parameters, highlighting a wide range of plant physiological responses, are combined: for example leaf temperature with spectral fluorescence detected at particular wavelength bands. In the following sections, the results obtained with the different imaging techniques will be described first. Thereafter multi-sensor stress imaging will be illustrated, and the stress factors and their induced responses will be summarized in a tabular form: the stress catalogue. 


\section{Thermography}

Canopy or leaf temperature, as measured using thermography (thermal infrared sensing or imaging), provides a powerful monitoring tool for a broad range of plant stresses that affect any aspect of plant water relations. The basis underlying most uses of leaf temperature as a stress detection tool is that leaf temperature is strongly affected by transpiration, which itself is primarily regulated by stomatal conductance, with leaf temperature increasing as transpiration rate decreases [21]. Leaf temperature is a particularly sensitive indicator of changes in stomatal conductance because latent heat loss is a large component of the overall leaf energy balance that determines leaf temperature [22]. Current thermal camera models commonly have a temperature resolution of $0.1^{\circ} \mathrm{C}$ which is adequate to reveal transpirational changes or heterogeneity at the leaf surface. Spatial resolution however is rather limited in comparison with the currently available cameras for the visual spectrum, but proved to be sufficient for leaf to plant level monitoring, and can be compensated for by automation approaches in which multiple images are captured.

At a canopy scale where image pixels may include both leaf and soil, observed temperatures can also change as a result of varying vegetative ground cover, with increasing proportions of soil (as the canopy becomes sparser or as leaves wilt) tending to lead to higher temperatures. An approach to correct the observed average temperatures to better reflect leaf temperatures only has been proposed by [23], while for higher resolution data the image analysis approaches described in [24] can be useful.

The development of methods for stress diagnosis or quantification based on leaf temperature observations under field conditions is complicated by the fact that environmental variables, including air temperature, net radiation absorbed (which is a function of leaf angle), boundary layer resistance (a function of leaf size and wind speed) and air vapor pressure 


\section{Abiotic stress detection}

As already indicated, many stresses, including especially water deficits, lead to stomatal closure. Therefore all such stresses can, in principle, be detected and quantified by thermal sensing of stomatal closure, albeit in relative mode [28, 29]. In many cases an observed leaf temperature increase can be related to water stress, even though a water deficit may not have been the original primary stress (see below). This multiple causation also highlights the challenge of identifying particular stress classes.

Because drought causes stomatal closure and leaf temperature rise, thermal sensing has been of particular interest for many years as a tool for scheduling irrigation [25, 30]. A fundamental difficulty in the use of stomatal conductance (and hence of leaf temperature) as a 
proxy indicator of the causal stress is that the relationship between stomatal conductance and leaf water status varies between species. Some plant species minimize the depression of leaf water potential as the water supply decreases by stomatal closure, for these so-called "isohydric" plants [31] stomatal closure (and hence leaf temperature) is a very good indicator of water supply. On the other hand, so called "anisohydric" species do not close their stomata until the water deficit is severe; in such cases stomatal closure is not a sensitive indicator of water deficit stress (see [32]). Sunflower, most crop plants (e.g. wheat, barley and soybean) and the grapevine cultivar 'Shiraz' are commonly classified as anisohydric, while maize and many temperate trees, together with the grapevine cultivar 'Grenache' are typically characterized as isohydric $[31,33]$. The latter are, given their tight stomatal control, suitable for thermal sensing for irrigation control [34].

Thermal sensing can also be used to study the spatial and temporal dynamics of plant freezing, due to the local heat generation as tissue water freezes [35]. In addition, the rates of water loss from leaves can change in response to atmospheric pollution (e.g. [36]), nutritional status [37] and salinity [38]. Other abiotic stresses, such as the uptake of herbicides can also be detected by thermal imaging. For example, methylurea herbicide uptake induces a temperature increase emerging from the main veins and spreading to finally affect the whole leaf [39]. Although this effect was visualized with more contrast by using parallel chlorophyll fluorescence (Chl-F) imaging (see below), the clear spatial and temporal pattern of the development of the thermal effect adds to the information available from the thermal signal and helps to distinguish this from other stresses.

\section{Biotic stress detection}

Leaf temperature has been used as an indicator of several biotic stresses [21, 40-43]. Local, rapidly expanding increases in leaf temperature develop at tobacco mosaic virus 
(TMV) infection sites in resistant tobacco, before visual symptoms can be discerned [44].

This symptom is synchronous with an increase in Chl-F and an increase in UV-excited fluorescence (see below). As underlying mechanism, a coincident accumulation of the phenolic compound salicylic acid (SA) was revealed which reduced transpiration by its known stomatal closing activity. Phenolic compounds typically accumulate during resistance responses of plants to pathogens, and multiple reports indicate a reduction in stomatal conductance or aperture, pointing at a possibly general mechanism of symptom manifestation. Apart from phenolics, other classes of chemicals interfere with stomatal control; these include various pathogen toxins [45] such as the fungal toxins which cause (internal) tissue degradation, leading to local leaf temperature decreases at early stages of Cercospora infection in sugar beet $[46,47]$. Concomitantly Chl-F was shown to increase (see below). An increase of the thermal signal was observed, both at early stages of infection with the oomycete Pseudoperonospora cubensis causing downy mildew in cucumber [48] and in the case of the fungus Phyllosticta acting on two tree species [49].

Plant surface degradation and leaf cell death is commonly a consequence of certain specific or multiple biotic aggressions. Such damage frequently decreases leaf temperature locally due to evaporation of leaf water from the damaged tissue. Examples where temperature decreases occur include the late stages of TMV infection and upon spontaneous, disease-like lesion formation in Arabidopsis and tobacco [42, 44]. Similarly, damage by mechanical leaf wounding can lead to an immediate temperature increase, followed by a localized decrease due to water loss from damaged cells, that progressively disappears again upon wound healing $[49,50]$. In case of arthropod-induced gall formation a temperature decrease has also been described [49].

As well as being of value for the topical diagnosis and monitoring of local (leaf) infections, thermal imaging can also provide information relating to root diseases and rots 
caused by fungi or oomycetes and for vascular wilts induced by the proliferation of bacteria or fungi. This is because these all impact on water uptake and transport, and ultimately result in a decrease in transpiration (reviewed in [21]). Toxic compounds absorbed by the root system of plants will also gradually affect leaf transpiration [39].

\section{Diagnostic capability}

From the above it follows that (especially) single-time point leaf temperature measurements by themselves are not usually diagnostic, and normally require some ancillary information to determine the precise cause of any observed temperature change. As is apparent from the detailed symptoms, especially of the various biotic stresses outlined above, additional diagnostic information can be obtained from the temporal and spatial dynamics of the temperature changes. In general leaf level-stresses, such as caused by leaf infections, tend to induce a (persistent) heterogeneous response pattern, whereas root level stresses evolve towards a more homogeneous leaf-level response. The spatial and temporal pattern of the stress response can most likely provide a first approach to further discriminate different stressors. Dedicated image processing algorithms will enable detection and discrimination of (the kinetics of) different patterns.

\section{Fluorescence}

Leaves emit fluorescence upon absorption of radiation ranging from the UV to the visible; however this dissipation typically accounts for only a few percent of the actual energy uptake. Fluorescence always has a longer wavelength (i.e. lower energy per quantum) than the absorbed light (“Stokes-shift”).

Reliable detection of fluorescence emission requires a homogeneous illumination of the monitored leaf area(s), implying a dedicated illumination system. As mentioned for 


\section{thermography, in the case of field measurements, confounding influences from the environment (weather conditions, time of day) limit the detectability of stress factors.}

Several compounds within leaves fluoresce, and one can distinguish between the most important emissions including blue-green fluorescence emitted by cell wall bound ferulic acid $[51,52]$ and red-far red fluorescence emitted by chlorophyll (Chl) $a$ in photosystem II [53]. The intensity of fluorescence generally depends on (a) the concentration of the fluorophores, (b) the temperature of the leaf, (c) the penetration of the excitation light into the leaf and (d) the fluorescence emission from different depths of the leaf. Chlorophyll fluorescence (Chl-F) is a particularly powerful probe for investigating activity and integrity of the photosynthetic system. The intensity of this Chl-F varies as a function of the various alternative pathways which compete with fluorescence for de-excitation of radiant energy absorbed by the Chl antenna pigments. These include (e) use of energy to drive photosynthetic electron transport (photochemical quenching), and (f) non-radiative de-excitation resulting in heat loss (nonphotochemical quenching - NFQ). The magnitude of fluorescence is quenched from its maximum $\left(F_{m}\right.$ - which occurs when the primary electron acceptor is fully reduced) both by increasing photosynthetic electron transport and by non-photochemical quenching (including photoinhibition) dependent on $\mathrm{pH}$ and xanthophyll de-epoxidation in the thylakoids. Parameters such as the efficiency of photosystem II (PS II) and rates of electron transport can be readily obtained from $F_{m}$ together with the minimal fluorescence $\left(F_{o}\right)$ and the steady state fluorescence $\left(F_{s}\right)$ and the variable fluorescence $\left(F_{v}=F_{m}-F_{o}\right)$ using the formulae outlined earlier $[54,58]$.

Fluorescence images have been used as a tool to detect stress susceptibility in different plants, comparing genotypes or mutants [59, 61]. Further reviews on biotic and abiotic stress effects as monitored by fluorescence imaging have been presented earlier $[61,70]$. Chl-F therefore primarily assesses effects on photosynthetic function while UV-fluorescence primarily 
assesses changes in chemical composition; either of these may be modified by abiotic and biotic stresses [71].

\section{Abiotic stress detection}

Many environmental stresses affect leaf composition and photosynthesis and can therefore be monitored using fluorescence imaging; among the most important are drought and mineral nutrition. In addition high light becomes particularly damaging to the photosynthetic apparatus when photosynthesis is already inhibited (e.g. as a result of low temperatures or drought-induced stomatal closure). The excess light leads to photoinhibitory damage to the photosystems - a process than can be readily detected as a decrease in Chl-F $[65,72,73]$ and as a reduction in maximum quantum yield of PS II $\left(F_{v} / F_{m}\right.$ which was introduced by [54]). Importantly, plants under stress display an enhanced sensitivity to photoinhibition. As an example, the characteristics of photoinhibition and recovery in relation to cold exposure and acclimation have been derived from the differences in maximum quantum yield of PS II $F_{\Downarrow} / F_{m}$, detected from images of Chl-F [74].

Plants have evolved countermeasures to avoid light-induced damage. Increased sun exposure of leaves leads to a lower intensity of UV-excited Chl-F [20, 75-77], since UVabsorbing substances accumulated in the epidermis shield the Chl-containing mesophyll, and thus reduce fluorescence excitation by UV. UV-B treatment was shown to lead to an increased blue-green fluorescence [78]. The effect of excess light together with the formation of reactive oxygen species could be monitored by a decrease of photosynthesis via Chl-F images [79-82].

The most prevalent abiotic stress under natural conditions is water shortage. Although drought can affect photosynthetic rate, this is initially at least, primarily through stomatal closure with rather little effect on the activity of the photosystems as measured by $F_{v} / F_{m}$ (e.g. [83]). Nevertheless drought stress can lead to an increase in blue-green fluorescence, a 
decrease of Chl-F [75, 84-86] and a decrease of variable Chl-F [87-89]. A particularly useful measure of stress is the photochemical yield parameter, which is expressed as $\left(1-F_{s}\right) / F_{m}$ [56]. A decrease in Chl-F and its derived parameters for photochemical quenching, and an increase in non-photochemical quenching have been demonstrated in leaves of roses undergoing progressive water stress [90].

In addition to sufficient water supply, nutrients should be available in a balanced way to sustain optimal plant growth. Nitrogen deficiency can be recognized by a higher blue-green fluorescence and higher Chl-F at $690 \mathrm{~nm}$ [91-93]. Blue-green fluorescence increases because of changes in secondary metabolism induced by biotic or abiotic stress [94]; Chl-F at $690 \mathrm{~nm}$ increases due to a lower $\mathrm{Chl}$ content of the leaves, which results in less re-absorption of Chl-F (for a review see [95]). Low temperatures and gaseous pollutants can also affect photosynthesis and Chl-F emission (e.g. $[96,97])$. In addition, inhibition of photosynthesis by heavy metal uptake was demonstrated by fluorescence imaging [98]. A decrease of Chl-F as detected by photography was taken as an indicator of chilling [59], and upon ozone-induced damage of Brassica plants and beech trees the maximum quantum yield of PS II $F_{v} / F_{m}$ was significantly reduced $[99,100]$. This was also observed at the cellular level at the very early stages of ozone stress [101], and more generally, ozone-damage was detected by an increase in the Chl-F [102]. Mechanical damage to plant foliage can be caused by both biotic (e.g. insect damage) and abiotic factors (e.g. hail damage), but is commonly caused by windinduced movements leading to tearing damage of leaves. An artificially wounded leaf site first displays an increase in fluorescence emission, followed by a decrease to zero fluorescence in the regions where the cells were irreversibly damaged and subsequently died [103]. Cells proximal to a wound are characterized by a rapid induction of quantum efficiency of PS II upon actinic illumination after dark adaptation in Arabidopsis plants, revealing the power of fluorescence imaging to monitor changes in fluorescence induction kinetics [104]. 
Herbicides which inhibit photosynthetic activity (like DCMU or diuron $[=3-(3,4-$ dichlorophenyl)-1,1-dimethylurea] and linuron) can be detected by an increase in Chl-F. With time-lapse imaging of the Chl-F one can follow uptake and degradation of these inhibitors [39, 61, 105-108]. To assess herbicide efficiency, the effects of multiple compounds can be tracked in screening approaches [109].

\section{Biotic stress detection}

Again, the use of fluorescence for detection of biotic stresses, including both arthropod and microbial attacks primarily depends on their effects on photosynthesis, Arthropod wounding of leaves, mainly by chewing can lead to reductions in quantum efficiency of PS II ([110]; Aldea et al. 2006). The leaf areas around the holes created by caterpillars are characterized by a lower PS II activity, as visualized by Chl-F images [111]. Even footsteps of herbivore insects can be detected by an increased Chl-F [112]. In other cases, leaves affected by mite attack or by the tobacco whitefly can be recognized by the increase of blue fluorescence in a characteristic pattern related to the arthropod feeding behavior [65]. The response of the plant to localized wounding was monitored by Chl-F imaging as a decrease of the plant's photosynthetic activity [79, 80, 82]. Infection of sugar beet plants with root nematodes also induced an increase in Chl-F emission [113]. Any factor interfering with root water or nutrient uptake can thus potentially be revealed at an early stage by monitoring at leaf level.

Damage caused by micro-organisms is the second but equally important source of biotic plant yield losses. Effects of viruses, bacteria, fungi and oomycetes on plant leaf physiology have been visualized with Chl-F imaging. For example, the infection with a virulent strain of the bacterium Pseudomonas syringae could be monitored by a decrease in the maximum quantum yield for PS II $F \mathrm{~V} / F_{m}$ [114-116]. The infection of Arabidopsis plants with Pseudomonas syringae was monitored by Chl-F and the different infection phases by 
analyzing the most contrasting images [117]. This research highlighted the possibility of assessing the relative merit of a wide range of chlorophyll fluorescence parameters (including NFQ and Maximum yield of PSII) generated by an elaborate measuring protocol. Indications were found that certain parameters could excel in signaling the onset of the early stages of stress buildup upon bacterial infection. However, spatial variability inherent to measuring conditions and plant material characteristics (including illumination heterogeneity linked to heterogeneity in leaf morphology) reduced the discriminating power and prevented the derivation of a reliable signature or classifier. Thus, it is premature to select a particular fluorescence parameter as a signature for a given class of stressors; in-depth research will be needed.

Virus infection can be followed by means of fluorescence imaging (e.g. infection of Chinese cabbage with turnip yellow mosaic virus: [118]). During the early stages of TMV infection of resistant tobacco (Nicotiana tabacum) plants, an increase in Chl-F and blue-green fluorescence could be observed along with the rise of the thermal signal [44, 119]. Thereafter, the blue-green fluorescence remained at a high level, but as cell death progressed, leaf temperature decreased sharply at the infected loci, as did the Chl-F. Photosynthetic damage induced by mosaic viruses in susceptible plants was also detected by a variation in variable Chl-F [120-123]. Systemic infection of pepper mild mottle virus (PMMoV) in tobacco (Nicotiana benthamiana) plants could be revealed by Chl-F imaging, as a dynamic increase emanating from the main veins [43].

Fungi are generally considered more damaging to crop yields than viral infections, due to their rapid spread and propagation. An early increase of Chl-F was observed upon infection of sugar beet plants with the fungus Cercospora [46, 47]. The decrease of the photosynthetic electron transport upon infection with fungi was demonstrated by Chl-F images representing the photochemical yield parameter $\left(1-F_{s}\right) / F_{m}$ (bean plants infected with Colletotrichum 
lindemuthianum: [124]), the maximum quantum yield of PS II $F_{\mathrm{V}} / F_{m}$ (tomato leaves infected with Botrytis cinerea: [125] or barley leaves infected with Blumeria graminis: [126]) or $\left(F_{m}^{\prime}{ }^{-}\right.$ $\left.F^{\prime}\right) / F_{m}^{\prime}$ (measurements obtained during full-spectrum photosynthetic illumination in tobacco leaves infected with Phytophtora nicotianae: [127]). An increase in blue-green fluorescence has been reported in images of grapevine infected with powdery mildew (Uncinula necator, [128]). Many fungi exert their damaging effects through the secretion of toxins. The action of these fungal phytotoxins could be visualized by fluorescence imaging [129]. Destruxin (a phytotoxin of the fungus Alternaria brassica, which causes significant damage to Brassica crops) in a concentration as low as $0.05 \mathrm{mg} \mathrm{l}^{-1}$ induced an increase of the imaged Chl-F ratio $F_{0} / F_{m}[130]$. As a further example, the efficiency of PS II was decreased upon infection of oat leaves with crown rust Puccinia coronata [131]. Various phases of infection could be followed by imaging of Chl-F during infection of bean leaves with bean rust (Uromyces appendiculatus) [132].

In an agricultural context, some plants are considered pests since they compete with the cultivated crops. Chl-F imaging can be advantageously used to visualize the speed of herbicide uptake and to quantify its effects. The penetration of the herbicide diuron, which inhibits PS II activity, can be followed in a time-lapse sequence of fluorescence images, showing the increase of Chl-F in the affected leaf tissue [106].

\section{Diagnostic capability}

As pointed out above for thermal imaging, the physiological processes (especially photosynthesis) detected by fluorescence are potentially affected by a wide range of biotic and abiotic stresses. An explorative approach in which multiple chlorophyll fluorescence imaging derived parameters are quantified and plotted according to a spider diagram provide a visual signature of the stress impact and have the potential for automated recognition $[115,117]$. For comparative purposes different stressors have to be measured according to the same 
measuring protocol and under similar conditions to be able to draw conclusions and to expand on the preliminary stress class classification of Table1. In addition effective methods for distinguishing between different causes of the symptoms detected again depend on both the utilization of the temporal and spatial characteristics of the response and the use of complementary signals (such as thermal imagery, blue-green fluorescence and reflectance indices) that respond to different physiological processes. A combination of temporal measurements and multiple imaging techniques likely will allow to derive timedependent signatures typical for a particular stress factor, and provide enough redundancy to overcome the confounding effects of measuring conditions. 


\section{Future development: Multi-sensor monitoring}

With the ongoing technical development, imaging is more and more replacing the usual point measurement devices. Imaging allows measuring multiple samples (plants, leaves or leaf regions) simultaneously with a high two-dimensional resolution, and thus provides both the statistical distribution of the signal and information on the spatial variation. The use of imaging lends itself to a multi-sensor approach where images are obtained using different sensors (thermal and fluorescence) and overlaid to obtain a wide range of information for each area of the object. This maximizes the opportunities for discriminating stresses. A promising technique in this respect seems also the 'combinatorial imaging' by searching the most contrasting images taken with different protocols, as illustrated for chlorophyll fluorescence parameters [117], and the analysis of time sequence images [133]. The latter is advantageously combined with the derivation of parameters describing image statistical information, for example maximum temperature difference (MTD) as a measure of heterogeneity in thermal images [48]. A similar approach can be applied to chlorophyll fluorescence (parameter) images. Developing strategies of signature definition and recognition based on dedicated models and training datasets is gaining importance as an approach for stress factor discrimination [115], [19 and references therein].

When considering field or greenhouse measurements, adequate monitoring of environmental data is of prime importance to ascertain comparability of the obtained data to earlier or future results. The same pertains to closed environment measurements when considering integration of results obtained by different research groups on monitoring multiple plant-stressor combinations into a global overview that aims at a first-line identification of stressor classes. 


\section{Thermal imaging}

Thermography detects infrared radiation within the 3 to 14 micrometer range, the exact wavelength sensitivity depending on the chosen model, and can readily reveal temperature distributions at plant canopy to leaf level, without the need for any illumination. Many current models have a sensitivity of $0.1{ }^{\circ} \mathrm{C}$ which is adequate for leaf temperature heterogeneity visualization. Thermal cameras are increasingly popular with industrial, maintenance and safety monitoring, which tends to further lower their price and increases the availability of higher resolution detectors.

\section{Fluorescence imaging}

A fluorescence imaging system includes an excitation light source(s), a detector equipped to measure only at specific wavebands (usually achieved by inserting filter(s) in front of the camera), and a computer for controlling the measurement, the data acquisition and the data analysis (see e.g. [66]). The excitation light distribution over the target surface needs to be as homogeneous as possible to avoid masking the heterogeneity of the photosynthetic processes underlying the chlorophyll fluorescence emission.

The spectral range of the excitation light source determines the fluorescence that can be measured. When measuring Chl-F blue or short wavelength red excitation is used most frequently, because Chls absorb in these regions with the highest quantum efficiency. With UV radiation both blue-green fluorescence and Chl-F can be detected. However, when using UV excitation the intensity of Chl-F strongly depends on the presence of UV absorbing substances in the epidermis which cause UV shielding of the Chl in the mesophyll tissue below.

The light sources are usually operated in pulsed mode in order to eliminate ambient and reflected background light. As light sources either light emitting diodes (LEDs) or lamps 
(Xenon or halogen) fitted with band-pass filters are used. The fluorescence images are detected by monochrome charged coupled device (CCD) cameras combined with different band-pass filters (e.g. a high-pass red filter blocking all light with wavelength smaller than $650 \mathrm{~nm}$ for Chl-F detection) and synchronized with the excitation light pulses. Cooled CCDs are used for the determination of particularly low fluorescence signals (e.g. $\mathrm{F}_{0}$ ) [67]. CCDs with an image intensifier unit allow shorter integration time, and photon counting for measuring extremely short and low signals, respectively.

When using imaging to monitor stress responses, it is beneficial to compare several repeats and treatments or cultivars with differing resistance levels within a single experiment. Either high-resolution sensors or automation can accommodate screening approaches. The latter setup can be realized by robotized systems that move the sensor, or alternatively the plants.

Manual analysis of many images is generally time consuming, and especially with thermal images it is often difficult to separate leaf area from background. To solve these problems, a semi-automated method for image analysis was developed [24]. In this method, information from images of different type is combined to identify the area of interest. First, two different images (e.g. thermal and visible or thermal and fluorescence) representing the same area are overlaid using pre-selected reference (or "ground control") points. Second, the leaf area is separated from background using for example supervised classification for the visible image or pixel intensity thresholding in the fluorescence image. Finally, the identified leaf area is used to extract leaf-specific information from the other image, for example to calculate the temperature statistics of leaves in the thermal image. In cases where the positions of the cameras (thermal, fluorescence) are fixed in relation to each other [46], the method can be fully automated and allows rapid analysis of large number of images. In addition, specific 
masks can be obtained for discriminating shadow versus sunlit leaves under field conditions [134].

As described above, although the individual imaging techniques are able to reveal symptoms at early stages for a wide range of stresses effective discrimination between causal stresses is improved by the use of multiple sensors (such as thermography and chlorophyll fluorescence imaging) that monitor different physiological processes. For example both water stress and nitrogen deficiency can reduce the Chl concentration (which is revealed by changes in Chl-F Imaging), but water stress typically has a more pronounced and swift effect on stomatal closure (detected by thermography), given the fact that only water stress leads to leaf wilting. Water stress will also inhibit photosynthesis by stomatal limitation of $\mathrm{CO}_{2}$ uptake, which will affect Chl-F emission. As a consequence the kinetics of Chl-F emission will likely differ between water stress and nitrogen deficiency.

\section{Examples for multi-sensor imaging}

Dynamics of stomatal patchiness, induced by changes in environmental factors, were visualized simultaneously by thermal and chlorophyll fluorescence imaging. [135]. Both techniques provide spatial information for the interpretation of heterogeneity of stomatal and possibly linked photosynthetic responses, as well as of excess light energy dissipation mechanisms [136].

Both a viral (TMV) and a fungal (Cercospora) infection lead to the enhancement of Chl-F emission, followed by a subsequent decrease. The thermal picture shows a marked contrast in response, revealing a temperature increase after viral ingress in tobacco, versus a strong local cooling for the fungal infection in sugar beet (see Fig. 1). Fungal Botrytis cinerea infection in common bean resulted in a similar pattern for thermal and chlorophyll fluorescence as compared to the viral infection example mentioned above [103]. However, UV-excited 
fluorescence would likely be able to discern these two plant-pathogen interactions, based on the specificity of accumulating fluorescing compounds upon TMV-infection [119]. The 3 examples from Figure 1 illustrate that both thermography and Chl-F imaging reveal the infection at an early stage, with Chl-F imaging providing a higher spatial resolution, while thermography visualizes a slightly more extended affected region.

The quantification of stress-induced tissue damage can be dramatically enhanced by choosing a different imaging sensor or waveband. In general, Chl-F provides excellent contrast in comparison with visual images. Under certain circumstances, however, green fluorescence imaging after UV-excitation proves superior in revealing damage due to its ability to detect specific highly fluorescing compounds induced by a particular stress. In Figure 2, spontaneous cell death is apparent in the visual image of Arabidopsis $l s d$ mutants, but thresholding the symptoms from the green fluorescence resolves the symptoms better from the unaffected leaf areas, whereas the chlorophyll fluorescence image displays very little contrast and suffers from signal emission from the background owing to algal growth on the substrate. The affected area calculated per $l s d$ plant, by taking the ratio of the 2 thresholded images (green fluorescence over green channel of the visual reflectance image), is 11 and $12 \%$, respectively.

An optimal sensor-combination for discriminating a set of stresses can be chosen on the basis of a thorough understanding of the various physiological causes and effects of each stress. Key responses are summarized in Table 1 which represents the basis for a stresscatalogue. 


\section{Conclusion}

The multi-sensor imaging equipment can be used as a first early-warning system to pick up signals of plants in stress. As a consequence of its mobility that allows a wide range of action, especially in a horticultural or agricultural setting, an imaging sensor will detect emerging stresses, and at the same time allow targeted sampling for further diagnosis. With the aid of a stress catalogue, based on previously established stress responses under controlled or standard conditions (Table 1), a first coarse identification of the stress class will be facilitated. The stress catalogue will however need to be linked to a performant knowledge model or expert system that makes optimal usage of the sensor fusion approach, to derive the specific signatures needed for a sufficient level of discrimination. As a next step, the stressor can be identified by using tissue analysis (nutrient deficiencies) or diagnostic tests (pathogens). Therefore the multi-sensor approach could lead to a timely, localized and specific treatment, benefiting both culture economics and the environment and will become a valuable tool for the near future. 


\section{Acknowledgements}

The work described here was funded by the European Commission through a Research Training Network (STRESSIMAGING), contract HPRN-CT-2002-00254.

S.L. was a junior researcher at the Botanical Institute II, University of Karlsruhe, D-76128

Karlsruhe, Germany 

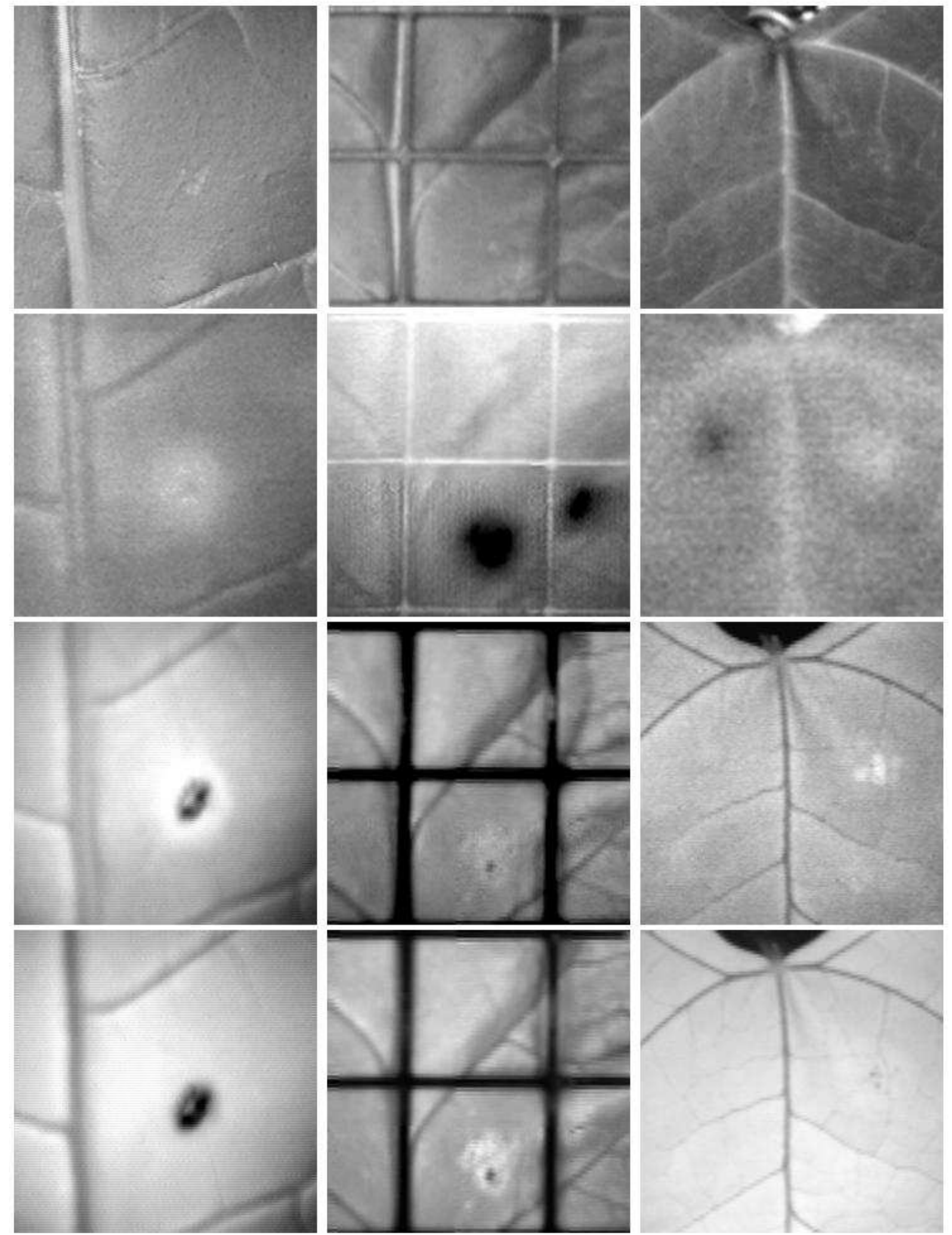

Figure 1. Comparison of presymptomatic symptoms of 3 plant pathogen interactions. Each column displays from top to bottom visual color image, thermal image and chlorophyll fluorescence image at respectively low and high excitation intensity. 
Left column: 54 hours after infection, the TMV-tobacco (Nicotiana tabacum) interaction results in a local temperature increase of maximum $0.5^{\circ} \mathrm{C}$ above the non-affected area of the leaf (corresponding with a 2 fold increase in pixel intensity) (second row). The increase extends beyond the visually affected area (image first row). The area of chlorophyll fluorescence decrease is also more extended than the visual damage, and expanding further outward is a halo of increased fluorescence (third row, halo presents an 1.5 fold increase in pixel intensity compared to unaffected tissue). Chlorophyll fluorescence under high intensity illumination only show the extent of tissue death (fourth row) (see also [46]).

Middle column: Cercospora beticola infection of sugar beet (Beta vulgaris) at 7days after infection shows a local decrease in leaf temperature of maximum $1^{\circ} \mathrm{C}$ (second row), while the visual effect is limited to a pin-point lesion (first row), which can also be seen as a small spot of lower chlorophyll fluorescence (third row). An increase in chlorophyll fluorescence is visible around this spot, and is more clearly visible at higher intensity illumination (fourth row); chlorophyll fluorescence intensity increases at least 3 fold compared with the unaffected leaf area (see also [46]).

Right column: Botrytis cinerea infection of common bean (Phaseolus vulgaris) $21 \mathrm{~h}$ after infection. An increase in local, leaf temperature is apparent (second row, maximum increase of $0.3^{\circ} \mathrm{C}$ ), while a few co-located spots of increased chlorophyll fluorescence are detectable (third row, intensity increase 2 fold over unaffected tissue). As a reference a wounding spot is included on the other side of the main leaf vein, and visible as a cold spot in the thermal picture (second row). The visible damage (first row) corresponds to the black spots in the ChlF image captured at high light-intensity (fourth row) (see also [103]). 


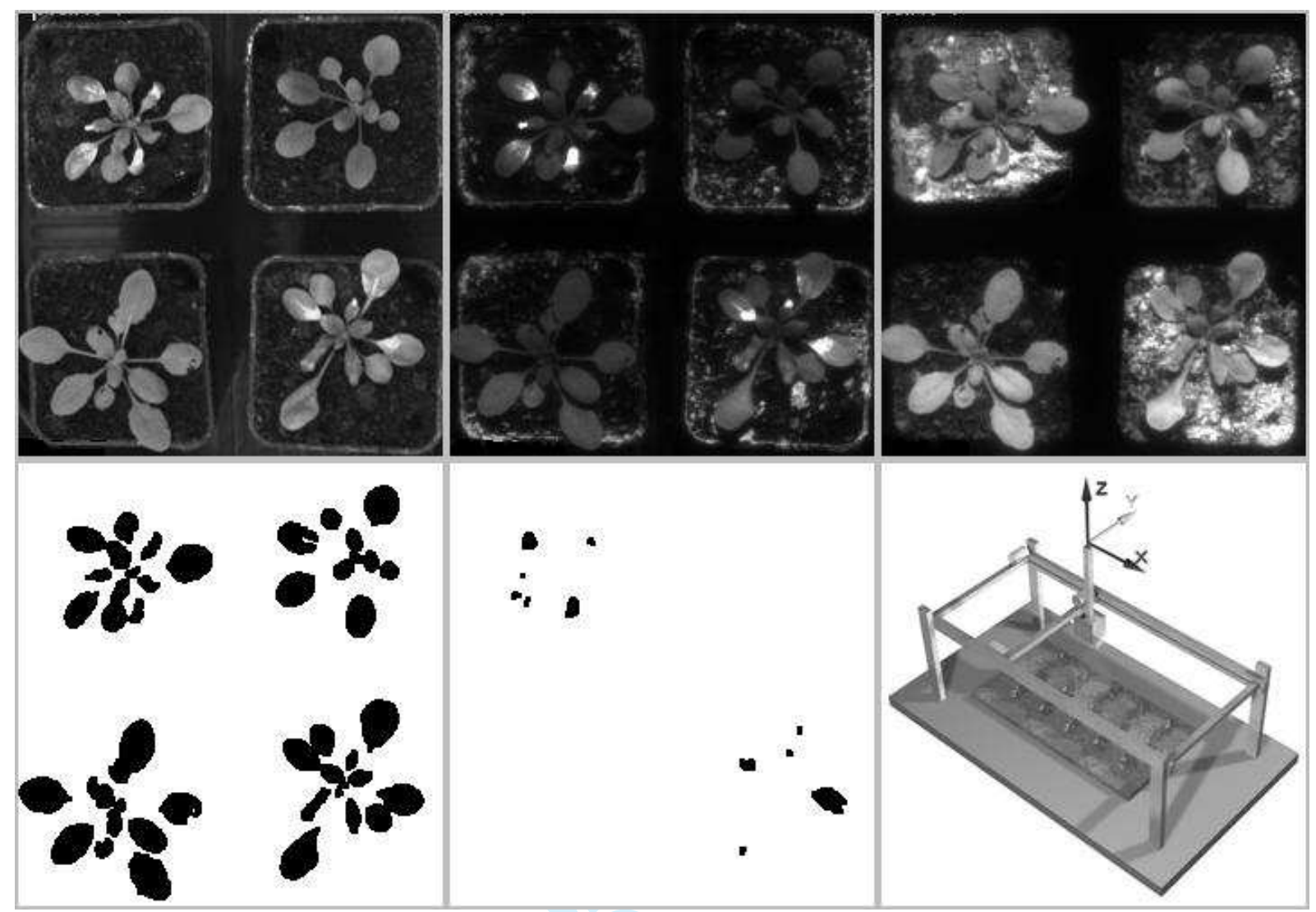

Figure 2. Arabidopsis plants as imaged with a multispectral fluorescence imaging system. In each panel, upper left and lower right position feature a spontaneous cell death mutant lsd (lesions simulating disease resistance, [42]; the other 2 plants are the Col-0 wild type from which this mutant was derived. Upper left: color reflectance image, middle panel: green fluorescence emission (550nm), right panel: chlorophyll fluorescence emission (690nm). The lower panels show thresholding of respectively color video and green fluorescence image, the latter indicating the leaf area affected by cell death. Thresholding of the chlorophyll fluorescence image includes part of the growing medium background and displays little or no contrast between affected and unaffected leaf areas, as is already evident from the depicted original fluorescence image. The lower right panel shows a schematic robotized system applicable for multi-sensor imaging. 


\section{Tables}


Table 1. Summary of stress effects and their detection by thermography and fluorescence imaging.

\begin{tabular}{|c|c|c|c|c|}
\hline & \multicolumn{2}{|l|}{ Thermography } & \multicolumn{2}{|l|}{ Fluorescence } \\
\hline \multicolumn{5}{|l|}{ Abiotic stress } \\
\hline Water stress & $\begin{array}{l}\text { Temperature rise (primary } \\
\text { response in "isohydric plants) }\end{array}$ & $\begin{array}{l}{[26,} \\
\text { 30] }\end{array}$ & $\begin{array}{l}\text { Increase in blue-green-F, decrease of Chl-F, decrease of } \\
\text { variable Chl-F, increase of non-photochemical quenching }\end{array}$ & {$[75,84-90,137]$} \\
\hline Sun exposure & & & $\begin{array}{l}\text { Decrease of UV-excited Chl-F, increase of blue-green } \\
\text { fluorescence, detection of reactive oxygen species via } \\
\text { fluorescence dyes }\end{array}$ & {$[75,76,78,138]$} \\
\hline Photoinhibition & $\sqrt{2}$ & & $\begin{array}{l}\text { Decrease of Chl -F, decrease of variable fluorescence, } \\
\text { detection of reactive oxygen species via fluorescence dyes }\end{array}$ & {$[65,73,74,138,139]$} \\
\hline Photooxidation & & & $\begin{array}{l}\text { Decrease of photosynthetic electron transport detected by } \\
\text { Chl-F, detection of reactive oxygen species via fluorescent } \\
\text { dyes }\end{array}$ & [79-81] \\
\hline Heavy metal uptake & & & $\begin{array}{l}\text { Decrease of photosynthetic electron transport detected by } \\
\text { Chl-F }\end{array}$ & [98] \\
\hline Salinity stress & Rise (not consistent) & {$[40]$} & $\sqrt{x+20}$ & \\
\hline Freezing & Rise (freezing exotherm) & [35] & $\left(x^{2}\right)$ & \\
\hline Chilling & & & Decrease of variable Chl-F & [139] \\
\hline Nitrogen deficiency & $\begin{array}{l}\text { Tendency to rise (may relate to } \\
\text { the reduced leaf area effect) }\end{array}$ & {$[40]$} & Higher blue-green-F and higher Chl-F at $690 \mathrm{~nm}$ & {$[91,93]$} \\
\hline $\begin{array}{l}\text { Gaseous pollutants } \\
\left(\mathrm{NO}_{2}, \mathrm{SO}_{2}, \mathrm{O}_{3}\right)\end{array}$ & $\begin{array}{l}\text { Rise (result of stomatal closure } \\
\text { with often increased stomatal } \\
\text { heterogeneity) }\end{array}$ & $\begin{array}{l}{[36,} \\
96, \\
97]\end{array}$ & Chl-F increase & {$[99,102]$} \\
\hline Wounding & $\begin{array}{l}\text { Temperature decrease due to } \\
\text { water loss }\end{array}$ & $\begin{array}{l}{[50,} \\
140]\end{array}$ & $\begin{array}{l}\text { Decrease of photosynthetic electron transport detected by } \\
\text { Chl-F, rapid induction of quantum efficiency of } \\
\text { photosystem II }\end{array}$ & {$[79,80,82,104]$} \\
\hline Herbicides & Temperature increase & [39] & Diuron or linuron: increase of Chl-F & $\begin{array}{l}39,61,102,105- \\
108]\end{array}$ \\
\hline \multicolumn{5}{|l|}{ Biotic stress } \\
\hline Insect attack & & & Increase of blue-F, change of photosynthetic parameters & {$[65,110,111]$} \\
\hline
\end{tabular}




\begin{tabular}{|c|c|c|c|c|}
\hline & & & derived from Chl-F images & \\
\hline $\begin{array}{l}\text { Vascular wilt } \\
\text { diseases and root rots }\end{array}$ & $\begin{array}{l}\text { Raise temperatures as lead to } \\
\text { water deficits and stomatal } \\
\text { closure }\end{array}$ & {$[40]$} & & \\
\hline $\begin{array}{l}\text { Fungal foliar } \\
\text { infection }\end{array}$ & Temperature decrease & $\begin{array}{l}{[46,} \\
48]\end{array}$ & $\begin{array}{l}\text { Increase of Chl-F } \\
\text { decrease of variable Chl-F, increase of blue-green-F }\end{array}$ & $\begin{array}{l}{[132] ;[131] ;[124] ;} \\
{[130] ;} \\
{[125] ;[46] ;[127] ;[12} \\
6] ;[128]\end{array}$ \\
\hline Viral infection & $\begin{array}{l}\text { TMV: Initial temperature rise, } \\
\text { follo-wed by decrease upon cell } \\
\text { death }\end{array}$ & [44] & $\begin{array}{l}\text { Variation in Chl-F parameters related to photosynthesis, } \\
\text { increase of Chl-F and blue-green-F }\end{array}$ & {$[43,118,121-123]$} \\
\hline Bacterial infection & $\begin{array}{l}\text { Erwinia: Presymptomatic } \\
\text { temperature decrease }\end{array}$ & {$[141]$} & decrease of variable fluorescence & [114-117] \\
\hline
\end{tabular}




\section{References}

[1] Selye, H., The Stress of Life, Mc Graw Hill, New York 1956.

[2] Larcher, W., Physiological Plant Ecology: Ecophysiology and Stress

Physiology of Functional Groups, Springer, Berlin 2003.

[3] Lichtenthaler, H. K. (Ed.), Vegetation Stress, G. Fischer, Stuttgart 1995.

[4] Hale, M. G., Orcutt, D.M. (Ed.), The Physiology of Plants under Stress, Wiley, New York 1987.

[5] Tenhunen, J. D., Catarino, F.M., Lange, O.L., Oechel, W.C. (Ed.), Plant response to stress: Functional analysis in Mediterranean ecosystems, Springer, Berlin 1987.

[6] Jones, H. G. (Ed.), Plants under Stress: Biochemistry, Physiology and Ecology and their Application to Plant Improvement, Cambridge University Press 1989.

[7] Alscher, R. G., Cumming, J.R. (Ed.), Stress Responses in Plants: Adaptation and Acclimation Mechanisms, Wiley-Liss, New-York 1990.

[8] Fowden, L. (Ed.), Plant Adaptation to Environmental Stress, Chapman \& Hall, London 1993.

[9] Brunold, C. (Ed.), Stress bei Pflanzen: Ökologie, Physiologie, Biochemie, Molekularbiologie, Haupt, Bern 1996.

[10] Csermely, P. (Ed.), Stress of Life: From Molecules to Man, New York Academy of Sciences, New York 1998.

[11] Lerner, H. R. (Ed.), Plant Responses to Environmental Stress: From Phytohormones to Genome Reorganization, Marcel Dekker, New York 1999. 
[12] Smallwood, M. F., Calvert, C.M., Bowles, D.J. (Ed.), Plant Responses to Environmental Stress, BIOS Scientific, Oxford 1999.

[13] Yunus, M. (Ed.), Environmental Stress: Indication, Mitigation, and Ecoconservation, Kluwer, Dordrecht 2000.

[14] Marcelle, R. (Ed.), Effects of Stress on Photosynthesis, Nijhoff, The Hague 1983.

[15] Satoh, K., Murata, N.K. (Ed.), Stress Responses of Photosynthetic

Organisms: Molecular Mechanisms and Molecular Regulations, Elsevier, Amsterdam 1998.

[16] Timmermann, B. N. (Ed.), Phytochemical Adaptations to Stress, Plenum Press, New York 1984.

[17] Cherry, J. H. (Ed.), Environmental Stress in Plants: Biochemical and Physiological Mechanisms, Springer, Berlin 1989.

[18] Treshow, M., Anderson, F.K., Plant Stress from Air Pollution, Wiley, Chichester 1989.

[19] Chaerle, L., Leinonen, I., Jones, H. G., Van Der Straeten, D., Monitoring and screening plant populations with combined thermal and chlorophyll fluorescence imaging. J. Exp. Bot. 2007, 58, 773-784.

[20] Lenk, S., Chaerle, L., Pfundel, E. E., Langsdorf, G., et al., Multispectral fluorescence and reflectance imaging at the leaf level and its possible applications. J. Exp. Bot. 2007, 58, 807-814.

[21] Jones, H. G., Application of thermal imaging and infrared sensing in plant physiology and ecophysiology. Adv. Bot. Res. 2004, 41, 107-163. 
[22] Jones, H. G., Plants and Microclimate : a Quantitative Approach to Environmental Plant Physiology, Cambridge university press, Cambridge 1992. [23] Moran, M. S., Clarke, T. R., Inoue, Y., Vidal, A., Estimating crop water deficit using the relation between surface-air temperature and spectral vegetation index. Remote Sens. Environ. 1994, 49, 246-263.

[24] Leinonen, I., Jones, H. G., Combining thermal and visible imagery for estimating canopy temperature and identifying plant stress. J. Exp. Bot. 2004, 55, $1423-1431$.

[25] Idso, S. B., Jackson, R. D., Pinter, P. J., Reginato, R. J., Hatfield, J. L., Normalizing the stress-degree-day parameter for environmental variability. Agr. Meteorol. 1981, 24, 45-55.

[26] Jones, H. G., Use of thermography for quantitative studies of spatial and temporal variation of stomatal conductance over leaf surfaces. Plant Cell Environ. 1999, 22, 1043-1055.

[27] Leinonen, I., Grant, O. M., Tagliavia, C. P. P., Chaves, M. M., Jones, H. G., Estimating stomatal conductance with thermal imagery. Plant Cell Environ. 2006, $29,1508-1518$.

[28] Chaerle, L., Saibo, N., Van Der Straeten, D., Tuning the pores: towards engineering plants for improved water use efficiency. Trends Biotechnol. 2005, $23,308-315$.

[29] Grant, O. M., Chaves, M. M., Jones, H. G., Optimizing thermal imaging as a technique for detecting stomatal closure induced by drought stress under greenhouse conditions. Physiol. Plant. 2006, 127, 507-518. 
[30] Jones, H. G., Irrigation scheduling: advantages and pitfalls of plant-based methods. J. Exp. Bot. 2004, 55, 2427-2436.

[31] Tardieu, F., Simonneau, T., Variability among species of stomatal control under fluctuating soil water status and evaporative demand: modelling isohydric and anisohydric behaviours. J. Exp. Bot. 1998, 49, 419-432.

[32] Jones, H. G., Irrigation scheduling - Comparison of soil, plant and atmosphere monitoring approaches Acta Hort. (ISHS) 2008, 391-403.

[33] Schultz, H. R., Differences in hydraulic architecture account for nearisohydric and anisohydric behaviour of two field-grown Vitis vinifera L. cultivars during drought. Plant Cell Environ. 2003, 26, 1393-1405.

[34] Chaerle, L., Van Der Straeten, D., Regulating plant water status by stomatal control, in: Jenks, M. A., Hasegawa, P.M., Mohan Jain, S. (Ed.), Advances in Molecular Breeding Toward Drought and Salt Tolerant Crops, Springer Netherlands 2007, pp. 73-90.

[35] Fuller, M. P., Wisniewski, M., The use of infrared thermal imaging in the study of ice nucleation and freezing of plants. J. Therm. Biol. 1998, 23, 81-89. [36] Omasa, K., Hashimoto, Y., Aiga, I., Image instrumentation of plants exposed to air pollutants I. Quantification of physiological information included in thermal infrared image. Res. Rep. Nat. Inst. Environ. Stud. 1984, 66.

[37] Wakiyama, Y., Infrared remote sensing of canopy temperature in paddy field and relationship between leaf temperature and leaf color. J. Agr. Meteorol. 2002, $58,185-194$. 
[38] Sharma, S., Soil salinity effects on transpiration and net photosynthetic rates, stomatal conductance and $\mathrm{Na}+$ and $\mathrm{Cl}-$ contents in durum wheat. Biol. plant. 1996, 38, 519-523.

[39] Chaerle, L., Hulsen, K., Hermans, C., Strasser, R. J., et al., Robotized timelapse imaging to assess in-planta uptake of phenylurea herbicides and their microbial degradation. Physiol. Plant. 2003, 118, 613-619.

[40] Nilsson, H. E., Remote sensing and image analysis in plant pathology. Аnnu. Rev. Phytopathol. 1995, 33, 489-527.

[41] Chaerle, L., Van Der Straeten, D., Imaging techniques and the early detection of plant stress. Trends Plant Sci. 2000, 5, 495-501.

[42] Chaerle, L., De Boever, F., Van Montagu, M., Van Der Straeten, D., Thermographic visualisation of cell death in tobacco and Arabidopsis. Plant Cell Environ. 2001, 24, 15-26.

[43] Chaerle, L., Pineda, M., Romero-Aranda, R., Van Der Straeten, D., Barón, M., Robotized thermal and chlorophyll fluorescence imaging of pepper mild mottle virus infection in Nicotiana benthamiana. Plant Cell Physiol. 2006, 47, 1323-1336.

[44] Chaerle, L., Van Caeneghem, W., Messens, E., Lambers, H., et al., Presymptomatic visualization of plant-virus interactions by thermography. Nature Biotechnol. 1999, 17, 813-816.

[45] Chaerle, L., Van Der Straeten, D., Seeing is believing: imaging techniques to monitor plant health. Biochim.Biophys. Acta-Gene Struct. Express. 2001, 1519, 153-166. 
[46] Chaerle, L., Hagenbeek, D., De Bruyne, E., Valcke, R., Van Der Straeten, D., Thermal and chlorophyll-fluorescence imaging distinguish plant-pathogen interactions at an early stage. Plant Cell Physiol. 2004, 45, 887-896. [47] Chaerle, L., Hagenbeek, D., De Bruyne, E., Van Der Straeten, D., Chlorophyll fluorescence imaging for disease-resistance screening of sugar beet. Plant Cell Tissue Organ Cult. 2007, 91, 97-106.

[48] Oerke, E. C., Steiner, U., Dehne, H. W., Lindenthal, M., Thermal imaging of cucumber leaves affected by downy mildew and environmental conditions. $J$. Exp. Bot. 2006, 57, 2121-2132.

[49] Aldea, M., Hamilton, J. G., Resti, J. P., Zangerl, A. R., et al., Comparison of photosynthetic damage from arthropod herbivory and pathogen infection in understory hardwood saplings. Oecologia 2006, 149, 221-232.

[50] Chaerle, L., De Boever, F., Van Der Straeten, D., Infrared detection of early biotic stress in plants. Thermology International 2002, 12, 100-106.

[51] Morales, F., Cerovic, Z. G., Moya, I., Time-resolved blue-green fluorescence of sugar beet (Beta vulgaris L) leaves. Spectroscopic evidence for the presence of ferulic acid as the main fluorophore of the epidermis. Biochim. Biophys. ActaBioenerg. 1996, 1273, 251-262.

[52] Lichtenthaler, H. K., Schweiger, J., Cell wall bound ferulic acid, the major substance of the blue-green fluorescence emission of plants. J. Plant Physiol. $1998,152,272-282$.

[53] Papageorgiou, G., Govindjee (Ed.), Chlorophyll a Fluorescence - A

Signature of Photosynthesis, Springer, Dordrecht 2004. 
[54] Kitajima, M., Butler, W. L., Quenching of chlorophyll fluorescence and primary photochemistry in chloroplasts by dibromothymoquinone. Biochim. Biophys. Acta 1975, 376, 105-115.

[55] Schreiber, U., Chlorophyll fluorescence yield changes as a tool in plant physiology. - I. The measuring system. Photosynth. Res. 1983, 4, 361-373.

[56] Meyer, S., Genty, B., Heterogeneous inhibition of photosynthesis over the leaf surface of Rosa rubiginosa L. during water stress and abscisic acid treatment: induction of a metabolic component by limitation of $\mathrm{CO}_{2}$ diffusion. Planta 1999, 210, 126-131.

[57] Horton, P., Ruban, A. V., Walters, R. G., Regulation of light harvesting in green plants. Annu. Rev. Plant Physiol. Plant Molec. Biol. 1996, 47, 655-684.

[58] Maxwell, K., Johnson, G. N., Chlorophyll fluorescence - a practical guide. J. Exp. Bot. 2000, 51, 659-668.

[59] Gibbons, G. C., Smillie, R. M., Chlorophyll fluorescence photography to detect mutants, chilling injury and heat stress. Carlsberg Res. Commun. 1980, 45, 269-282.

[60] Balota, M., Sowinska, M., Buschmann, C., Lichtenthaler, H.K., Heisel, F., Babani, F., Fluorescence techniques as suitable methods to discriminate wheat genotypes under drought and high temperature condition. Proc. SPIE 1999, 3707, 103-113.

[61] Baker, N. R., Rosenqvist, E., Applications of chlorophyll fluorescence can improve crop production strategies: an examination of future possibilities. J. Exp. Bot. 2004, 55, 1607-1621. 
[62] Daley, P. F., Chlorophyll fluorescence analysis and imaging in plant stress and disease. Can. J. Plant Pathol. 1995, 17, 167-173.

[63] Ning, L., Edwards, G. E., Strobel, G. A., Daley, L. S., Callis, J. B., Imaging fluorometer to detect pathological and physiological change in plants. Appl. Spectrosc. 1995, 49, 1381-1389.

[64] Lichtenthaler, H. K., Lang, M., Sowinska, M., Heisel, F., Miehe, J. A., Detection of vegetation stress via a new high resolution fluorescence imaging system. J. Plant Physiol. 1996, 148, 599-612.

[65] Buschmann, C., Lichtenthaler, H. K., Principles and characteristics of multicolour fluorescence imaging of plants. J. Plant Physiol. 1998, 152, 297-314. [66] Nedbal, L., Whitmarsh, J., Chlorophyll fluorescence imaging of leaves and fruits, in: Papageorgiou, G. C., Govindjee (Ed.), Chlorophyll a fluorescence: A signature of photosynthesis, Springer, Dordrecht 2004, pp. 389-407. [67] Oxborough, K., Imaging of chlorophyll a fluorescence: theoretical and practical aspects of an emerging technique for the monitoring of photosynthetic performance. J. Exp. Bot. 2004, 55, 1195-1205.

[68] Oxborough, K., Using chlorophyll $a$ fluorescence imaging to monitor photosynthetic performances, in: Papageorgiou, G. C., Govindjee (Ed.), Chlorophyll a Fluorescence: A Signature of Photosynthesis, Springer, Dordrecht 2004, pp. 409-428.

[69] Lichtenthaler, H. K., Langsdorf, G., Lenk, S., Buschmann, C., Chlorophyll fluorescence imaging of photosynthetic activity with the flash-lamp fluorescence imaging system. Photosynthetica 2005, 43, 355-369. 
[70] Baker, N. R., Chlorophyll fluorescence: a probe of photosynthesis in vivo. Annu. Rev. Plant Biol. 2008, 59, 89-113.

[71] Buschmann, C., Langsdorf, G., Lichtenthaler, H. K., The blue, green, red and far-red fluorescence signatures of plant tissues, their multicolor fluorescence imaging and application for agrofood assessment, in: Zude, M. (Ed.), Optical Methods for Monitoring Fresh and processed Food - Basics and Applications for a better Understanding of non-destructive Sensing, Taylor\&Francis, CRC-Press, Boca Raton 2008, pp. 272-319.

[72] Buschmann, C., Induction kinetics of heat emission before and after photoinhibition in cotyledons of Raphanus sativus. Photosynth. Res. 1987, 14, 229-240.

[73] Osmond, B., Schwartz, O., Gunning, B., Photoinhibitory printing on leaves, visualised by chlorophyll fluorescence imaging and confocal microscopy, is due to diminished fluorescence from grana. Aust. J. Plant Physiol. 1999, 26, 717-724. [74] Gray, G. R., Hope, B. J., Qin, X. Q., Taylor, B. G., Whitehead, C. L., The characterization of photoinhibition and recovery during cold acclimation in Arabidopsis thaliana using chlorophyll fluorescence imaging. Physiol. Plant. 2003, 119, 365-375.

[75] Lang, M., Lichtenthaler, H. K., Sowinska, M., Heisel, F., Miehe, J. A., Fluorescence imaging of water and temperature stress in plant leaves. J. Plant Physiol. 1996, 148, 613-621. 
[76] Lenk, S., Buschmann, C., Distribution of UV-shielding of the epidermis of sun and shade leaves of the beech (Fagus sylvatica L.) as monitored by multicolour fluorescence imaging. J. Plant Physiol. 2006, 163, 1273-1283.

[77] Štroch, M., Lenk, S., Navrátil, M., Špunda, V., Buschmann, C., Epidermal UV-shielding and photosystem II adjustment in wild type and chlorina $f 2$ mutant of barley during exposure to increased PAR and UV radiation. Environ. Exp. Bot. 2008, 64, 271-278.

[78] Krizek, D. T., Middleton, E. M., Sandhu, R. K., Kim, M. S., Evaluating UV$\mathrm{B}$ effects and EDU protection in cucumber leaves using fluorescence images and fluorescence emission spectra. J. Plant Physiol. 2001, 158, 41-53.

[79] Fryer, M. J., Ball, L., Oxborough, K., Karpinski, S., et al., Control of ascorbate peroxidase 2 expression by hydrogen peroxide and leaf water status during excess light stress reveals a functional organisation of Arabidopsis leaves. Plant J. 2003, 33, 691-705.

[80] Fryer, M. J., Oxborough, K., Mullineaux, P. M., Baker, N. R., Imaging of photo-oxidative stress responses in leaves. J. Exp. Bot. 2002, 53, 1249-1254.

[81] Hideg, E., Schreiber, U., Parallel assessment of ROS formation and photosynthesis in leaves by fluorescence imaging. Photosynth. Res. 2007, 92, 103-108.

[82] Chang, C. C. C., Ball, L., Fryer, M. J., Baker, N. R., et al., Induction of ascorbate peroxidase 2 expression in wounded Arabidopsis leaves does not involve known wound-signalling pathways but is associated with changes in photosynthesis. Plant J. 2004, 38, 499-511. 
[83] Massacci, A., Jones, H. G., Use of simultaneous analysis of gas-exchange and chlorophyll fluorescence quenching for analysing the effects of water stress on photosynthesis in apple leaves. Trees - Struct. Funct. 1990, 4, 1-8. [84] Barták, M., Hajek, J., Gloser, J., Heterogeneity of chlorophyll fluorescence over thalli of several foliose macrolichens exposed to adverse environmental factors: Interspecific differences as related to thallus hydration and high irradiance. Photosynthetica 2000, 38, 531-537.

[85] Nejad, A. R., Harbinson, J., van Meeteren, U., Dynamics of spatial heterogeneity of stomatal closure in Tradescantia virginiana altered by growth at high relative air humidity. J. Exp. Bot. 2006, 57, 3669-3678.

[86] Georgieva, K., Lenk, S., Buschmann, C., Responses of the resurrection plant Haberlea rhodopensis to high irradiance. Photosynthetica 2008, 46, 208-215.

[87] Osmond, C. B., Kramer, D., Luttge, U., Reversible, water stress-induced nonuniform chlorophyll fluorescence quenching in wilting leaves of Potentilla reptans may not be due to patchy stomatal responses. Plant Biol. 1999, 1, 618624.

[88] Lichtenthaler, H. K., Babani, F., Detection of photosynthetic activity and water stress by imaging the red chlorophyll fluorescence. Plant Physiol. Biochem. 2000, 38, 889-895.

[89] Baker, N. R., Oxborough, K., Lawson, T., Morison, J. I. L., High resolution imaging of photosynthetic activities of tissues, cells and chloroplasts in leaves. $J$. Exp. Bot. 2001, 52, 615-621. 
[90] Calatayud, A., Roca, D., Martinez, P. F., Spatial-temporal variations in rose leaves under water stress conditions studied by chlorophyll fluorescence imaging. Plant Physiol. Biochem. 2006, 44, 564-573.

[91] Heisel, F., Sowinska, M., Miehé, J. A., Lang, M., Lichtenthaler, H. K., Detection of nutrient deficiencies of maize by laser induced fluorescence imaging. J. Plant Physiol. 1996, 148, 622-631.

[92] Langsdorf, G., Buschmann, C., Sowinska, M., Babani, F., et al., Multicolour fluorescence imaging of sugar beet leaves with different nitrogen status by flash lamp UV-excitation. Photosynthetica 2000, 38, 539-551.

[93] Corp, L. A., McMurtrey, J. E., Middleton, E. M., Mulchi, C. L., et al., Fluorescence sensing systems: In vivo detection of biophysical variations in field corn due to nitrogen supply. Remote Sens. Environ. 2003, 86, 470-479.

[94] Cerovic, Z. G., Samson, G., Morales, F., Tremblay, N., Moya, I., Ultravioletinduced fluorescence for plant monitoring: present state and prospects. Agronomie $1999,19,543-578$.

[95] Buschmann, C., Variability and application of the chlorophyll fluorescence emission ratio red/far-red of leaves. Photosynth. Res. 2007, 92, 261-271.

[96] Omasa, K., Hashimoto, Y., Aiga, I., A quantitative analysis of the relationships between $\mathrm{SO}_{2}$ or $\mathrm{NO}_{2}$ sorption and their acute effects on plant leaves using image instrumentation. Environ. Contr. Biol. 1981, 19, 59-67.

[97] Omasa, K., Hashimoto, Y., Aiga, I., A quantitative analysis of the relationships between $\mathrm{O}_{3}$ sorption and its acute effects on plant leaves using image instrumentation. Environ. Contr. Biol. 1981, 19, 85-92. 
[98] Valcke, R., Ciscato, M., Heisel, F., Miehé, J., Sowinska, M., Analysis of heavy metal stressed plants by fluorescence imaging. Proceedings of SPIE - Laser Radar Technology and Applications IV 1999, 3707, 82-90.

[99] Gielen, B., Vandermeiren, K., Horemans, N., D'Haese, D., et al., Chlorophyll a fluorescence imaging of ozone-stressed Brassica napus L. plants differing in glucosinolate concentrations. Plant Biol. 2006, 8, 698-705.

[100] Gielen, B., Low, M., Deckmyn, G., Metzger, U., et al., Chronic ozone exposure affects leaf senescence of adult beech trees: a chlorophyll fluorescence approach. J. Exp. Bot. 2007, 58, 785-795.

[101] Leipner, J., Oxborough, K., Baker, N. R., Primary sites of ozone-induced perturbations of photosynthesis in leaves: identification and characterization in Phaseolus vulgaris using high resolution chlorophyll fluorescence imaging. J. Exp. Bot. 2001, 52, 1689-1696.

[102] Kim, M. S., McMurtrey, J. E., Mulchi, C. L., Daughtry, C. S. T., et al., Steady-state multispectral fluorescence imaging system for plant leaves. Appl. Opt. 2001, 40, 157-166.

[103] Chaerle, L., Hagenbeek, D., Vanrobaeys, X., Van Der Straeten, D., Early detection of nutrient and biotic stress in Phaseolus vulgaris. Int. J. Remote Sens. 2007, 29, 3479-3492.

[104] Quilliam, R. S., Swarbrick, P. J., Scholes, J. D., Rolfe, S. A., Imaging photosynthesis in wounded leaves of Arabidopsis thaliana. J. Exp. Bot. 2006, 57, $55-69$. 
[105] Yanase, D., Andoh, A., Translocation of photosynthesis - inhibiting herbicides in wheat leaves measured by phytofluorography, the chlorophyll fluorescence imaging. Pest. Biochem. Physiol. 1992, 44, 60-67. [106] Lichtenthaler, H. K., Lang, M., Sowinska, M., Summ, P., et al., Uptake of the herbicide diuron as visualised by the fluorescence imaging technique. Bot. Acta 1997, 110, 158-163.

[107] Hulsen, K., Top, E. M., Hofte, M., Biodegradation of linuron in a Phaseolus bioassay detected by chlorophyll fluorescence. New Phytol. 2002, 154, 821-829. [108] Kim, J.-H., Jung, J.-E., Lee, C.-H., In vivo monitoring of the incorporation of chemicals into cucumber and rice leaves by chlorophyll fluorescence imaging. Korean J. Plant Biotechnol. 2002, 4, 173-179.

[109] Barbagallo, R. P., Oxborough, K., Pallett, K. E., Baker, N. R., Rapid, noninvasive screening for perturbations of metabolism and plant growth using chlorophyll fluorescence Imaging. Plant Physiol. 2003, 132, 485-493.

[110] Tang, J. Y., Zielinski, R. E., Zangerl, A. R., Crofts, A. R., et al., The differential effects of herbivory by first and fourth instars of Trichoplusia ni (Lepidoptera: Noctuidae) on photosynthesis in Arabidopsis thaliana. J. Exp. Bot. 2006, 57, 527-536.

[111] Zangerl, A. R., Hamilton, J. G., Miller, T. J., Crofts, A. R., et al., Impact of folivory on photosynthesis is greater than the sum of its holes. Proc. Natl. Acad. Sci. U.S.A. 2002, 99, 1088-1091.

[112] Bown, A. W., Hall, D. E., MacGregor, K. B., Insect footsteps on leaves stimulate the accumulation of 4-aminobutyrate and can be visualized through 
increased chlorophyll fluorescence and superoxide production Plant Physiol. $2002,129,1430-1434$.

[113] Schmitz, A., Tartachnyk, II, Kiewnick, S., Sikora, R. A., Kuhbauch, W., Detection of Heterodera schachdi infestation in sugar beet by means of laserinduced and pulse amplitude modulated chlorophyll fluorescence. Nematology 2006, 8, 273-286.

[114] Bonfig, K. B., Schreiber, U., Gabler, A., Roitsch, T., Berger, S., Infection with virulent and avirulent $P$. syringae strains differentially affects photosynthesis and sink metabolism in Arabidopsis leaves. Planta 2006, 225, 1-12.

[115] Berger, S., Benediktyova, Z., Matous, K., Bonfig, K., et al., Visualization of dynamics of plant-pathogen interaction by novel combination of chlorophyll fluorescence imaging and statistical analysis: differential effects of virulent and avirulent strains of $P$. syringae and of oxylipins on A. thaliana. J. Exp. Bot. 2007, $58,797-806$

[116] Rodríguez-Moreno, L., Pineda, M., Soukupová, J., Macho, A. P., et al., Early detection of bean infection by Pseudomonas syringae in asymptomatic leaf areas using chlorophyll fluorescence imaging. Photosynth. Res. 2006, 96, 27-35. [117] Matouš, K., Benediktyova, Z., Berger, S., Roitsch, T., Nedbal, L., Case study of combinatorial imaging: What protocol and what chlorophyll fluorescence image to use when visualizing infection of Arabidopsis thaliana by Pseudomonas syringae? Photosynth. Res. 2006, 90, 243-253. 
[118] Szigeti, Z., Almási, A., Sárvári, E., Changes in the photosynthetic function in leaves of Chinese cabbage infected with turnip yellow mosaic virus. Acta Biologica Szegediensis 2002, 46, 137-138.

[119] Chaerle, L., Lenk, S., Hagenbeek, D., Buschmann, C., Van Der Straeten, D., Multicolor fluorescence imaging for early detection of the hypersensitive reaction to tobacco mosaic virus. J. Plant Physiol. 2007, 164, 253-262.

[120] Balachandran, S., Osmond, C. B., Daley, P. F., Diagnosis of the earliest strain-specifc interactions between tobacco mosaic virus and chloroplasts of tobacco leaves in vivo by means of chlorophyll fluorescence imaging. Plant Physiol. 1994, 104, 1059-1065.

[121] Osmond, C. B., Daley, P. F., Badger, M. R., Lüttge, U., Chlorophyll fluorescence quenching during photosynthetic induction in leaves of Abutilon striatum Dicks. infected with abutilon mosaic virus, observed with a field-portable imaging system. Bot. Acta 1998, 111, 390-397.

[122] Lohaus, G., Heldt, H. W., Osmond, C. B., Infection with phloem limited abutilon mosaic virus causes localized carbohydrate accumulation in leaves of Abutilon striatum: Relationships to symptom development and effects on chlorophyll fluorescence quenching during photosynthetic induction. Plant Biol. 2000, 2, 161-167.

[123] Pérez-Bueno, M., Ciscato, M., vandeVen, M., García-Luque, I., et al., Imaging viral infection: studies on Nicotiana benthamiana plants infected with the pepper mild mottle tobamovirus. Photosynth. Res. 2006, 90, 111-123. 
[124] Meyer, S., Saccardy-Adji, K., Rizza, F., Genty, B., Inhibition of photosynthesis by Colletotrichum lindemuthianum in bean leaves determined by chlorophyll fluorescence imaging. Plant Cell Environ. 2001, 24, 947-955. [125] Berger, S., Papadopoulos, M., Schreiber, U., Kaiser, W., Roitsch, T., Complex regulation of gene expression, photosynthesis and sugar levels by pathogen infection in tomato. Physiol. Plant. 2004, 122, 419-428.

[126] Swarbrick, P. J., Schulze-Lefert, P., Scholes, J. D., Metabolic consequences of susceptibility and resistance (race-specific and broad-spectrum) in barley leaves challenged with powdery mildew. Plant Cell Environ. 2006, 29, 10611076.

[127] Scharte, J., Schon, H., Weis, E., Photosynthesis and carbohydrate metabolism in tobacco leaves during an incompatible interaction with Phytophthora nicotianae. Plant Cell Environ. 2005, 28, 1421-1435.

[128] Bélanger, M. C., Roger, J. M., Cartolaro, P., Viau, A. A., Bellon-Maurel, V., Detection of powdery mildew in grapevine using remotely sensed UV-induced fluorescence. Int. J. Remote Sens. 2008, 29, 1707-1724.

[129] Bowyer, W. J., Ning, L., Daley, L. S., Strobel, G. A., et al., In vivo fluorescence imaging for detection of damage to leaves by fungal phytotoxins. Spectroscopy 1998, 13, 36-44.

[130] Soukupova, J., Smatanova, S., Nedbal, L., Jegorov, A., Plant response to destruxins visualized by imaging of chlorophyll fluorescence. Physiol. Plant. 2003, 118, 399-405. 
[131] Scholes, J. D., Rolfe, S. A., Photosynthesis in localised regions of oat leaves infected with crown rust (Puccinia coronata): quantitative imaging of chlorophyll fluorescence. Planta 1996, 199, 573-582.

[132] Peterson, R. B., Aylor, D. E., Chlorophyll fluorescence induction in leaves of Phaseolus vulgaris infected with bean rust (Uromyces appendiculatus). Plant Physiol. 1995, 108, 163-171.

[133] Polder, G., van der Heijden, G. W. A. M., Jalink, H., Snel, J. F. H., Correcting and matching time sequence images of plant leaves using Penalized Likelihood Warping and Robust Point Matching. Comput. Electron. Agric. 2007, $55,1-15$.

[134] Moller, M., Alchanatis, V., Cohen, Y., Meron, M., et al., Use of thermal and visible imagery for estimating crop water status of irrigated grapevine. J. Exp. Bot. 2007, 58, 827-838.

[135] West, J. D., Peak, D., Peterson, J. Q., Mott, K. A., Dynamics of stomatal patches for a single surface of Xanthium strumarium L. leaves observed with fluorescence and thermal images. Plant Cell Environ. 2005, 28, 633-641. [136] Kana, R., Vass, I., Thermoimaging as a tool for studying light-induced heating of leaves Correlation of heat dissipation with the efficiency of photosystem II photochemistry and non-photochemical quenching. Environ. Exp. Bot. 2008, 64, 90-96.

[137] Hideg, E., Juhasz, M., Bornman, J. F., Asada, K., The distribution and possible origin of blue-green fluorescence in control and stressed barley leaves. Photochem. Photobiol. Sci. 2002, 1, 934-941. 
[138] Hideg, E., Barta, C., Kalai, T., Vass, I., et al., Detection of singlet oxygen and superoxide with fluorescent sensors in leaves under stress by photoinhibition or UV radiation. Plant Cell Physiol. 2002, 43, 1154-1164.

[139] Hogewoning, S. W., Harbinson, J., Insights on the development, kinetics, and variation of photoinhibition using chlorophyll fluorescence imaging of a chilled, variegated leaf. J. Exp. Bot. 2007, 58, 453-463.

[140] Chaerle, L., vande Ven, M., Valcke, R., Van Der Straeten, D., Visualisation of early stress responses in plant leaves. Proc. SPIE 2002, 4710, 417-423. [141] Boccara, M., Boue, C., Garmier, M., De Paepe, R., Boccara, A. C., Infra-red thermography revealed a, role for mitochondria in pre-symptomatic cooling during harpin-induced hypersensitive response. Plant J. 2001, 28, 663-670. 
Comparison of presymptomatic symptoms of 3 plant pathogen interactions. Each column displays from top to bottom visual colour image, thermal image and chlorophyll fluorescence image at respectively low and high excitation intensity.

Left column: 54 hours after infection, the TMV-tobacco (Nicotiana tabacum) interaction results in a local temperature increase (second row), beyond the visually affected area (image first row). The area of chlorophyll fluorescence decrease is also more extended than the visual damage, and expanding further outward is a halo of increased fluorescence (third row). Chlorophyll fluorescence under high intensity illumination only show the extent of tissue death (fourth row) (see also [46]). Middle column: Cercospora beticola infection of sugar beet (Beta vulgaris) at 7days after infection shows a local decrease in leaf temperature (second row), while the visual effect is limited to a pinpoint lesion (first row), which can also be seen as a small spot of lower chlorophyll fluorescence (third row). An increase in chlorophyll fluorescence is visible around this spot, and is more clearly visible at higher intensity illumination (fourth row) (see also [46]). 
Right column: Botrytis cinerea infection of common bean (Phaseolus vulgaris) $21 \mathrm{~h}$ after infection. An increase in local, leaf temperature is apparent (second row), while a few co-located spots of increased chlorophyll fluorescence are detectable (third row). As a reference a wounding spot is included on the other side of the main leaf vein, and visible as a cold spot in the thermal picture (second row). The visible damage (first row) corresponds to the black spots in the Chl-F image captured at high light-intensity (fourth row) (see also [102]).

$262 \times 345 \mathrm{~mm}(72 \times 72 \mathrm{DPI})$ 
Arabidopsis plants as imaged with a multispectral fluorescence imaging system. In each panel, upper left and lower right position feature a spontaneous cell death mutant Isd (lesions simulating disease resistance, [42]; the other 2 plants are the Col-0 wild type from which this mutant was derived. Upper left: color reflectance image, middle panel: green fluorescence emission (550nm), right panel: chlorophyll fluorescence emission $(690 \mathrm{~nm})$. The lower panels show thresholding of respectively color video and green fluorescence image, the latter indicating the leaf area affected by cell death. Thresholding of the chlorophyll fluorescence image includes part of the growing medium background and displays little or no contrast between affected and unaffected leaf areas, as is already evident from the depicted original fluorescence image. The lower right panel shows a schematic robotized system applicable for multi-sensor imaging. $254 \times 176 \mathrm{~mm}(72 \times 72 \mathrm{DPI})$ 